DOI: $110.2478 /$ ausp-2018-0022

\title{
More Than a Facebook Share: Exploring Virtual Linguistic Landscape
}

\author{
Enikő BIRÓ \\ Sapientia Hungarian University of Transylvania (Cluj-Napoca, Romania) \\ Department of Applied Linguistics \\ biro.eniko@ms.sapientia.ro
}

\begin{abstract}
This paper seeks to cross the boundaries of what we consider linguistic landscape (LL) and open new spaces, thus examining the Internet as a complex set of linguistic landscapes. The present study is the result of an exploratory research. Virtual linguistic landscape (VLL) provides opportunities for language display that are rare in the geographical LL. This study investigates multilingualism and language practices present on the periphery of cyberscapes analysed in this research (namely the social media), based on questionnaires carried out among bilingual university students at Sapientia University. The conclusion will offer suggestions for further research on how to extend the boundaries of LL studies to the digital domain.
\end{abstract}

Keywords: virtual linguistic landscape, bilinguals, social media, multilingual practices.

\section{Introduction}

The paper investigates the virtual linguistic landscape analysed in this research (namely the social media, considered as a public space) and aims to reveal digital language practices regarding L2, L3, etc. language choice of bilingual university students at Sapientia Hungarian University of Transylvania (henceforth: Sapientia HUT).

Linguistic landscape studies have expanded their boundaries since the wellknown milestone study by Landry-Bourhis (1997). The very early approaches of quantitative surveys and sign counting have moved towards a complex relationship between language, place, and people (Barni-Bagna 2015). Linguistic landscape "provides a prism of languages embedded in societies and situated in humanistic, social and political ecology of those who share, form, influence and are influenced by it" (Shohamy-Waksman 2009: 314). A more "global" approach to LL has been developed, leading to an expansion in the topics of analysis. The term 'linguistic' is 
now no longer limited to verbal and written languages but embraces the complexity of semiotic spaces as well as of people who are authors, actors, and users, all of which are part of LL analysis. The study of linguistic landscapes does not focus exclusively on displays of visible written language, but also multimodal, semiotic, other visual and even oral elements can be included in order to provide important insights and a different perspective on language awareness and multilingualism. For the study of multilingualism, LL offers a subfield of research, namely of minority languages and multilingualism within a minority setting. These data clarify the complex interaction of language, society, identity, and power. They mainly focus on how the linguistic landscape can elucidate power relationships between majority and minority groups of speakers (Gorter-Cenoz 2017: 238). Starting from "the language of public road signs, advertising billboards, street names, place names, commercial shop signs and public signs on governmental buildings" originally listed by Landry-Bourhis (1997) in their pioneer article, linguistic landscape studies arrived at a point where studies have already included as their interest of investigation a wide range of phenomena from graffiti (Pennycook 2010) to the language of tourist postcards (Jaworski 2010) or signs of classroom walls (Laihonen-Tódor 2017, Laihonen-Szabó 2017, Biró 2016); even sounds, music, and smells are incorporated nowadays. Finally, studies have come to analyse the phenomenon of the cyberspace (e.g. Ivković-Lotherington 2009, Troyer 2012). The term "cyberspace” was coined in the above mentioned Ivković-Lotherington article, and it refers to computermediated communication which takes place on the Web.

This paper aims to investigate the multilingual practices and language choices of minority bilingual students in the public context of the social media as part of the virtual linguistic landscape. The article is structured as follows: after explaining the definition of virtual linguistic landscape, the context of the research - the bilingual minority speakers and language learners at Sapientia HUT - is presented in order to contextualize the presence or absence, the need or the rejection of multilingualism and language learning practices created in the virtual linguistic landscape. This is followed by the description of the methodology and data. Then, the findings are presented, and, finally, the suggestions for further research to extend the boundaries of LL studies to the digital domain are discussed.

\section{Defining virtual linguistic landscape}

If we consider the virtual space as another dimension of communication, then it can be stated that virtual linguistic landscape defines the linguistic landscape of the virtual space just as linguistic landscape describes the linguistic cityscape or schoolscape, etc. However, there are some obvious characteristics which distinguish VLL from the traditional LL (see Table 1). 
Table 1. Distinction between linguistic landscape (LL) and virtual linguistic landscape (VLL)

\begin{tabular}{ll}
\hline \multicolumn{1}{c}{ LL } & \multicolumn{1}{c}{ VLL } \\
\hline $\begin{array}{l}\text { It is based on physical geographical } \\
\text { environment. }\end{array}$ & $\begin{array}{l}\text { It is a virtual world in which } \\
\text { computer-mediated communication } \\
\text { (CMC) takes place. }\end{array}$ \\
\hline $\begin{array}{l}\text { The elements of LL reflect spoken } \\
\text { language situations of the real world. }\end{array}$ & $\begin{array}{l}\text { VLL does not necessarily reflect the } \\
\text { spoken language situations of the real } \\
\text { world. }\end{array}$ \\
\hline $\begin{array}{l}\text { Signage is typically more fixed and } \\
\text { stable. }\end{array}$ & $\begin{array}{l}\text { Signage is transitory, dynamic, can } \\
\text { be updated on a day-to-day basis, } \\
\text { generally at low costs. }\end{array}$ \\
\hline $\begin{array}{l}\text { Speakers are interacting within } \\
\text { demarcated spatial boundaries. }\end{array}$ & $\begin{array}{l}\text { VLL speakers are delocalized and } \\
\text { anyone from anywhere (with access to } \\
\text { the Internet) can enter and engage in it. }\end{array}$ \\
\hline
\end{tabular}

The concrete distinction between the physical (geographical) linguistic landscape and the virtual linguistic landscape (term also used by IvkovićLotherington in their article in 2009) has become relevant since studies focused on public signage in the online world in the context of LL. Ivković-Lotherington point out that online signage, online communication "transfer lived experiences onto the virtual domain" (2009: 20). Each space offers opportunities to use language, to construct and design space in very creative ways; therefore, landscapes become "web of significances where languages are used in different ways, conveying different meanings and with different aims in mind" (Gorter-Cenoz 2014: 167). By including the virtual signage in broadening linguistic landscape studies, more insights into language practices, signage creations, and language learning attempts of individuals, groups, or communities can be gained. In this environment, in this virtual linguistic landscape, multilingual communication takes place (IvkovićLotherington 2009). VLL leads to an increased breadth of multilingual interaction as it can be related to the diversity of languages "out there" or to the particular groups of users with the language resources at their disposal, while multilingual discourses can also be characterized by translanguaging, code-switching, or code-mixing. Moreover, Vandergriff states that these changes, namely the online digital practices, have turned the attention of language learning researchers towards the heightened importance of learner agency, and these views can inform language learning and language teaching in ways that pedagogy-driven approaches may not (Vandergiff 2016: 24). Vandergriff points out the importance of learner engagement with L2 or multilingual communities which initiate learners into L2 digital practices. Furthermore, online communicative practices may impact curricular expectations as online practices and online target-language communities cannot be excluded anymore. "The emergence of Web 2.0 and the 
growing access it provides to users across the globe affects how people learn an additional language. It has become easier than ever before to find and access instructional language-learning materials of all types and the web also offers an ever-increasing wealth of authentic materials" (Vandergiff 2016: 5). In the $21^{\text {st }}$ century, foreign languages' curricula must include the competence to participate in virtual communities. "L2 users will be expected to be able to navigate online spaces in order to find, evaluate, use, share and create content" (Vandergiff 2016: 6). Thus, technology transforms language learning and teaching by connecting learners with others in online multilingual spaces. The intersection of VLL and language learning may enhance students to experience increased language awareness due to vastly different conversational structures vs those encountered in formal educational settings, other opportunities for language choice and codeswitching, together with the clash of various personal, social, and cultural values. Because digital tools enable a dialogic process among learners and interlocutors, they have merged as the most promising way to foster extended learner discourse, and students have the opportunity to develop their repertoire. Multilingual practices of the virtual world are shaped by two constraints: first of all, being member of the virtual world means being networked, being digitally connected to others, and it requires a two-way communication. Secondly, it also means being in the network, being part of the virtual linguistic landscape of the social media, and of the Web in general, which refers to a one-way communication itself. Sites and apps designed for language learning (e.g. Duolingo) provide practice and materials or even facilitate connections between learners and other users, and even Facebook has groups dedicated to language learning.

Table 2. Some general features of the web evolution

\begin{tabular}{lll}
\hline \multicolumn{1}{c}{ Web 1.0 } & \multicolumn{1}{c}{ Web 2.0 } & \multicolumn{1}{c}{ Web 3.0 } \\
\hline Mostly read-only & Widely read-write & $\begin{array}{l}\text { Portable and personal/ } \\
\text { semantic web }\end{array}$ \\
\hline Home pages & Wikis/Blogs & Live streams \\
\hline Web forms & Web applications & Smart applications \\
\hline Directories & Tagging & User behaviour \\
\hline One-way communication & Two-way & $\begin{array}{l}\text { Three-way } \\
\text { communication/ } \\
\text { communication/social media facilitates } \\
\end{array}$ \\
& media & \begin{tabular}{l} 
communication \\
\hline
\end{tabular} \\
\hline
\end{tabular}

The evolution of the web leaves no doubt that the inclusion of researching its linguistic landscape provides various research topics. The earlier web (Web 1.0) allowed users to connect to static websites, while Web 2.0 allows users to interact with the web. At the moment, we are already experiencing the facilities 
of Web 3.0 with its smart applications; and communication has already shown a three-way mode, where the social media facilitates communication (see Table 3). The next step, Web 4.0 has not arrived yet, but it is predicted that it would refer to the Internet of things (IoT), a symbiotic web which will allow the interaction between humans and machines in a symbiosis.

Therefore, virtual linguistic landscape research may take various routes. In order to study the virtual signage and its role in communication, the linguistic landscape of virtual/computer games, the overall linguistic landscape of the Internet (cyberscape of websites) can be considered. Linguistic landscape can also be defined by the specific physical places converging with their virtual counterparts (referring to digital linguistic landscape - geotagging, geographical metadata). Furthermore, virtual linguistic landscape studies may include the research of various social media, studying multilingualism in social networks, as we do not know very much about L2, L3 discourse on social media sites.

\section{The context of the research and data collection}

The research presented in this paper is a preliminary examination of the virtual linguistic landscape created and used by undergraduate bilingual students of Sapientia HUT. The majority of the students are from the three counties of Romania where Hungarians comprise the majority of the population: Covasna, Harghita, and Mureş counties. There are students from other regions of Romania, and some come from the neighbouring countries (see: Fazakas 2014). As the participants of this study are at different levels of bilingualism, the concept of individual bilingualism ${ }^{1}$ as defined by Skutnabb-Kangas-McCarty (2008: 4-5) is used to indicate different levels of L2 proficiency. Individual bilingualism refers to the use of two or more languages by an individual. Throughout this paper, the term "first language" (L1) is used to refer to Hungarian as the language "best known and/or most used" by the speakers in question, also called "mother tongue" and contrasted with the second language (L2), in our case, Romanian (Skutnabb-Kangas-McCarty 2008: 6).

The research was carried out in March 2018. A total of 118 questionnaires were filled in by $1^{\text {st }}$ and $2^{\text {nd }}$-year undergraduate students. As the present study is considered a pioneer survey, the number of the students is not a representative one. Therefore, the findings of this survey cannot be generalized, but major trends based on the collected data could be identified. The items of the questionnaire

1 Individual bi-/multilingualism, sometimes called plurilingualism, involves proficiency in and use of two or more languages by an individual. The term used by the authors does not always imply an equally high level of proficiency in all the relevant languages (Skutnabb-KangasMcCarty 2008). 
referred to personal background data (studies, year, gender, age); self-assessment (digital literacy, Romanian (L2) and English/German (L3) language proficiency); use and ownership of digital tools (e.g. How often do you use digital tools during language learning?); use of mobile applications, computer games for language learning (Do you consider playing computer games useful for language learning?); membership and use of the social media (Do you read English/Romanian posts?, Do you share English/Romanian posts?) as well as opinion regarding usefulness of social media in the process of language learning (Do you consider useful to integrate the social media (e.g. Facebook) into the practice of language learning - to share readings, relevant information?). Using data gained from participants' self-assessed language proficiency is an alternative type of assessment. An official definition of language proficiency was provided by the Council of Europe in the form of the Common European Framework of Reference for languages from 2001. This form is used in schools at the end of schooling as part of the final exam series during high school graduation. Therefore, it provides a reliable background for the participants of the research. They could reach back to it when they selfassessed their language proficiency. Second-language speakers believe more in a higher second-language proficiency than their actual level of proficiency as it provides them with functional communication within the context (DörnyeiUshioda 2011). Therefore, they reported a higher English proficiency than the actual level of their English knowledge, being able to communicate now and then with foreigners, able to watch movies in English, etc. Their Romanian proficiency, on the other hand, is lower, according to their self-assessment, as not being able to perform in daily communicative contexts. These data were completed by a snapshot Facebook profile case study of the participants (62 profiles), referring to the visual linguistic elements and signs of language choice of the participants included in the survey. Due to time restrictions, the following factors were taken into consideration: the languages used in Facebook profiles during this period; the language of the shared contents, the language of the descriptions accompanying their shares; the language choice of their public comments on the particular page.

In this present paper, the research questions refer to the following hypotheses: A. If we assume that VLL is multilingual, then social media use should show signs of multilingualism; B. If we assume that the users of the social media are multilinguals, then VLL builds up a huge virtual linguistic input/resource, which ultimately serves as language resource and educational platform for language learning. 


\section{Discussion of the results. Multilingual practices and the virtual linguistic landscape}

There were 42 male and 76 female students who participated in the survey with an age range between 19 and 28 years. They can be considered bilinguals, with Hungarian as L1 and with different levels of L2 (Romanian) language proficiency. According to their major (Chart 1), there were Agricultural Engineering students (from Sfântu-Gheorghe), students from Translating and Interpreting, Communication and Public Relations (from Târgu-Mureş) as well as students from Economics/Genetic Engineering, Romanian Language and Literature/ English Language and Literature, Universal Literature/English Language and Literature (from Miercurea Ciuc).

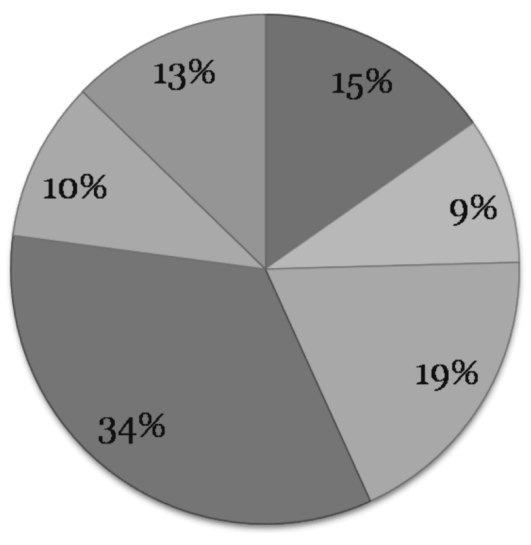

Agriculturalno. 18

$\square$ Communication no. 11

$\square$ Economics no. 22

$\square$ Translating no. 40

$\square$ Universal Lit.-English no. 12

$\square$ Romanian-English no. 15

Chart 1. Percentage of students participating in the survey based on their studies

The majority of the respondents described themselves as being on an intermediate-advanced level regarding digital literacy (76 students out of 118). Digital literacy was previously explained to them, stating that it refers to the ability of using the Internet and software such as Word or Excel. Their language proficiency was based on self-assessment (Chart 2). The Translating/Interpreting students and language students reported at least intermediate language proficiency, both in Romanian and English, as their studies required advanced language proficiency. 


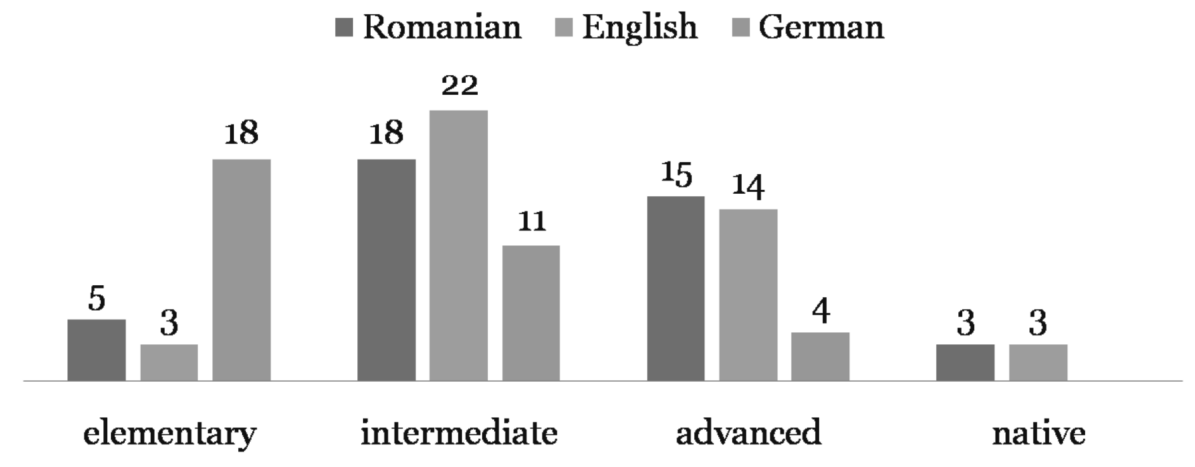

Chart 2. Translating and Interpreting students' (a total of 40 students) selfreported language proficiency in Romanian, English, and German

Agricultural Engineering students reported the lowest language proficiency, partially due to the non-existing prerequisite of advanced language command (English) at the start of their university studies. They live in Romanian villages or cities where the majority of the population is Hungarian, and therefore they lack the possibility of practising Romanian in their everyday communication (Chart 3).

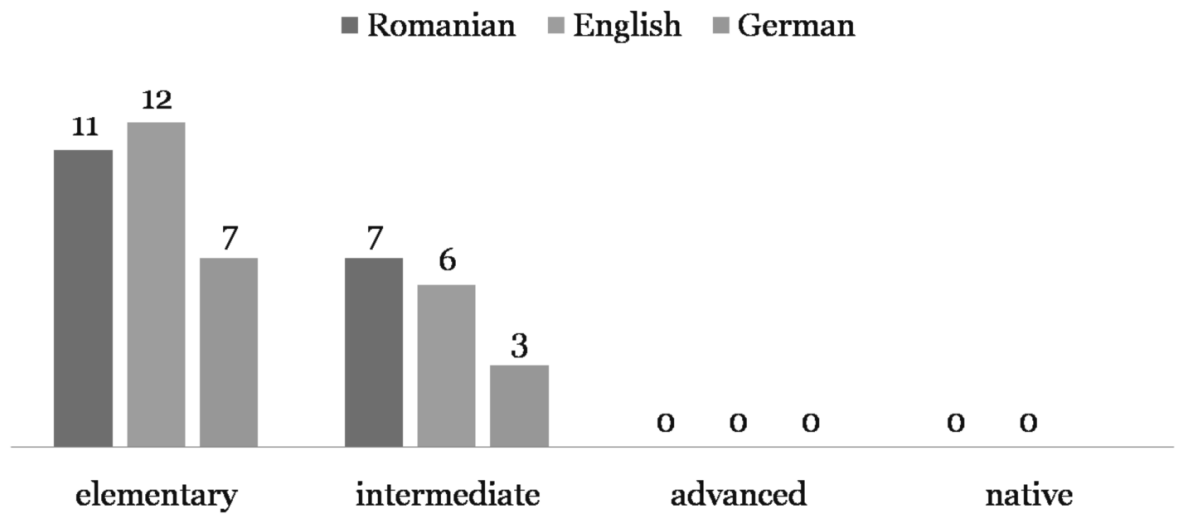

Chart 3. Agricultural Engineering students' (a total of 18 students) self-reported language proficiency in Romanian, English, and German

Keyboard-and-screen technologies are needed to build up the VLL in order to be networked and to be in the network. According to the data of the present research, $100 \%$ of the participants own a smartphone and laptop, while PCs and tablets are less popular $-43 \%$ of the students own a PC, and $27 \%$ of them have a tablet. They often use these devices to collect and study information online and use them during their academic studies. Due to their lack of language command either in 
Romanian or English or both, 15\% of the participants do not collect information in Romanian or English. However, this percentage has to be dealt with care as most of the participants are language students with intermediate or advanced language proficiency in L2 and L3. Regarding the conscious use of applications for language learning, they tend to use some of them, for example Duolingo. The majority of the students, $79 \%$ of them, consider these apps "not useful". They play or used to play computer games, but the majority finds them "not useful" in the process of language learning $(62 \%)$. The results of the questionnaire revealed their membership in one or more social media, with Facebook membership on the top (52\%), followed by Instagram (32\%), Snapchat (11\%), and Twitter (5\%). They continuously share and read contents on social platforms, e.g. Facebook; however, the majority shares and reads exclusively Hungarian contents; even language students exceed the majority only by $6 \%$. A total of $30 \%$ often reads and shares in other languages than Hungarian; however, $60 \%$ rarely reads and shares anything else than Hungarian contents, while 10\% never reads or shares in any other languages except for their mother tongue. Their opinion about the usefulness of social media in the process of language learning (Do you consider useful to integrate the social media (e.g. Facebook) into the practice of language learning?) revealed that $51 \%$ of the participants considers that it would be useful, $33 \%$ suggests that it would be useful to a certain degree, while $13 \%$ does not really find it useful, and $3 \%$ of them finds it totally useless. It can be stated that university students at Sapientia HUT use the Internet and the social media extensively to collect, read, and share information, although the extent of this use is determined by their language proficiency level. The use of applications has not gained popularity either because it requires a long-term perseverance or it presents an inconvenient way of language learning. However, the majority would take into consideration the further use of social media in language learning processes, which takes us back to the already mentioned learner agency, where the learner engagement with L2 or multilingual communities initiates learners into L2 or L3 digital practices (see: Vandergriff 2016: 24).

Data completed by a random sampling of public Facebook profiles of the participants served as a snapshot of the visual linguistic elements and signs of language choice of the participants. Their Facebook profiles build up the virtual linguistic landscape, which is public in nature but reflects the individual decisions of the account holder. As already mentioned, the following factors were taken into consideration: the languages used in Facebook profiles during this period; the language of the shared contents, the language of the descriptions accompanying their shares; the language choice of their public comments on a certain page. According to the findings, there were three types of users. The first type of users is language-confident (either in Romanian or in English or in both). Their Facebook content shows signs of language mixing, sharing in all languages 
they know; the descriptions are multilingual as well. However, their comments are generally Hungarian, rarely Romanian and only if the communication situation requires it, i.e. the partner speaks Romanian. The second type of users, mostly those who are not language students, share multilingual contents, sometimes even with multilingual descriptions or quotes. These are mainly used for creating their Facebook identities, therefore serving as a self-fashioning practice. However, they do not engage in other language practices than Hungarian. The third group of users is a group of typically Hungarian-based content builders; they rarely share anything in other languages. The members of this group are networked by Hungarian counterparts and are in the network of a virtual linguistic landscape with Hungarian linguistic elements. Future research will focus on the detailed analysis of the content of these profiles in order to gain more insight into the multilingual character of these virtual landscapes.

\section{Conclusions and implications for future work}

Assuming that VLL is multilingual, social media use should show signs of multilingualism. However, lack of language proficiency is still an obstacle to creating and using elements of the VLL. Sharing and reading in foreign languages is less prevalent than expected, and the content is used in identity creation or self-fashioning. A multilingual/bilingual user is trendy, and it should be peer- and group-supported. The identity created on social media pages is not an isolated phenomenon but it is characterized by intersubjectivity ${ }^{2}$ based on online interactions, called the collaborative authorship of the self. Theoretically, the multilingual virtual space created by the individual speakers provides more opportunity for multilingual practices, with content sharing, comments, etc.; still, the significant body of the contents is pragmatic-oriented and fulfils the needs of a monolingual community. The virtual linguistic landscape can build up a huge virtual linguistic input/linguistic resource which can serve as language resource and educational platform for language learning by imitating spontaneous LL language learning possibilities, creating endless possibilities of foreign language input for any language learners. Learners can choose the most adequate input for their personal needs and personal character. However, VLL in our study delineates - indicates - the boundaries of a linguistic community and marks the language status among coexisting language choices. Finding and sharing information in different languages does not really promote multilingualism for the students. Using the VLL as means of language learning is still far away from the everyday virtual linguistic practice. Speakers of a minority language will choose their

2 Intersubjectivity here refers to a relation between the self and other, which can mediate discourses of the self and of the social sharings in the social media. 
native language in order to be in the network and being networked. Therefore, the virtual linguistic landscape can be seen as a vehicle for the presentation of the self and as a community identity marker with the patterns of social interaction in which people engage in this particular space.

The study presented in this paper raises a number of questions. The reliability of the data is an issue as the study presented in this paper relies on self-reported data rather than direct observation. Future work needs to address the issue of small sample size in order to facilitate rigorous statistical analysis, in particular to verify the preliminary results suggested by the current data. Further research could directly examine the actual language practice of bilingual speakers coupled with a mapping of the languages of contacts in their online network. While this approach is likely to provide a rich source of data, the methodological and ethical issues require careful consideration. Moreover, the next research topics should cover the relationship between the multilingual practices and language learning of bilingual speakers. VLL can serve to a certain extent as an informal language learning environment where the actors of this landscape create their own "shares" and, together with other semiotic resources, become involved in the symbolic construction of multilingual spaces. Crossing the border between linguistic landscape and virtual linguistic landscape, a Facebook share will imply more than content sharing with all of its future possibilities.

\section{References}

Biró, Enikő. 2016. Learning schoolscapes in a minority setting. Acta Universitatis Sapientiae Philologica 8(2): 109-121.

Barni, Monica-Carla Bagna. 2015. The critical turn in LL: New methodologies and new items in LL. Linguistic Landscape 1(1-2): 6-18.

Dörnyei, Zoltán-Ema Ushioda. 2011. Teaching and Researching Motivation (2 ${ }^{\text {nd }}$ ed.). Harlow: Longman.

Fazakas, Noémi. 2014. Linguistic attitudes and ideologies of the students of the Sapientia Hungarian University of Transylvania. Acta Universitatis Sapientiae 6(3): 335-356.

Gorter, Durk-Jasone Cenoz. 2014. Linguistic landscapes inside multilingual schools. In Bernard Spolsky-Michal Tannenbaum-Ofra Inbar (eds), Challenges for Language Education and Policy: Making Space for People, 151-169. New York: Routledge.

Gorter, Durk-Jasone Cenoz. 2017. Linguistic landscape and multilingualism. In Durk Gorter-Jasone Cenoz-May Stephens (eds), Language Awareness and Multilingualism. Cham: Springer. 
Ivković, Dejan-Heather Lotherington. 2009. Multilingualism in cyberspace: Conceptualising the virtual linguistic landscape. International Journal of Multilingualism 6(1): 17-36.

Jaworski, Adam. 2010. Linguistic landscapes on postcards: Tourist mediation and the sociolinguistic communities of contact. Sociolinguistic Studies 4(3): 469-594.

Landry, Rodrigue-Richard Bourhis. 1997. Linguistic landscape and ethnolinguistic vitality: An empirical study. Journal of Language and Social Psychology 16(1): 23-49.

Laihonen, Petteri-Péter Szabó T. 2017. Investigating visual practices in educational settings: Schoolscapes, language ideologies and organizational cultures. In Marilyn Martin-Jones and Deirdre Martin (eds), Researching Multilingualism: Critical and Ethnographic Perspectives, 121-138. Routledge.

Laihonen, Petteri-Tódor Erika-Mária. 2017. The changing schoolscape in a Szekler village in Romania: Signs of diversity in rehungarization. International Journal of Bilingual Education and Bilingualism 20(3): 362-379.

Pennycook, Alastair. 2010. Spatial narrations: Graffscapes and city souls. In Jaworski, Adam and Crispin Thurlow (eds), Semiotic Landscapes: Language, Image, Space, 137-151. London: Continuum.

Shohamy, Elana-Shoshi Waksman. 2009. Linguistic landscape as an ecological arena. Modalities, meanings, negotiations, education. In Elana Shohamy and Durk Gorter (eds), Linguistic Landscape: Expanding the Scenery, 313-331. London: Routledge.

Skutnabb-Kangas, Tove-Teresa McCarty. 2008. Key concepts in bilingual education: Ideological, historical, epistemological, and empirical foundations. In Jim Cummins and Nancy Hornberger (eds), Language Policy and Political Issues in Education, 1, Encyclopedia of Language and Education, 3-17. New York: Springer.

Troyer, A. Robert. 2012. English in the Thai linguistic netscape. World Englishes 31(1): 93-112.

Vandegriff, Ilona. 2016. Second-Language Discourse in the Digital World: Linguistic and Social Practices in and beyond the Networked Classroom. Amsterdam: John Benjamins. 